\title{
A turbulent time: government sources post-2016 presidential election
}

\section{Abstract}

Purpose Since the 2016 presidential election, hyper-partisanship has become a regular facet of the political landscape with Democrats and Republicans in increasing conflict. The purpose of this paper is to determine if perception of government sources related to trust and credibility has changed since the 2016 election and if the experiences and strategies of librarians who teach or consult about government information has changed in response to this environment.

Design/Methodology/Approach A 24-question survey was distributed to garner qualitative and quantitative responses from librarians who teach or consult about government information in an academic environment. 122 responses were used for analysis.

Findings Academic librarians are seeing more concern from patrons about disappearing online government information and wider distrust of government information broadly. Librarians also noticed that the political leanings of students colors their perspective around government sources and that librarians also need to keep their political beliefs in check. Respondents emphasized a need for more government literacy and information literacy topics when discussing evaluation of government sources.

Research limitations/implications The data collection only included responses from academic librarians. Further research could include in-depth interviews and look at experiences in various library types.

Originality/Value With the timeliness of this topic, there has not been an in-depth investigation into how the Trump administration has changed user trust and perception of government sources from the librarian's point of view. This paper continues the conversation about how librarians can address the growing distrust of government information and give us insight into the effects of a turbulent political climate on government sources.

Keywords Academic libraries, Government information, Trust, Library instruction, Government literacy, Information literacy

Paper type Research paper

\section{Introduction}

Government information has always been a key part of academic research, but as many librarians know, they are often more complex in nature than other sources users may encounter. They vary in viewpoint and intent based on which agency or branch of government is publishing the information, and they also differ widely in scope and format. Students have not always 
questioned the reputability of government sources, often assuming that the government is an organization that publishes nonbiased, objective, "good" information. Since the rise in awareness of fake news, misinformation, and disinformation heightened by the 2016 presidential election, however, both instructors and students alike have begun to more seriously question the objectivity and reputability of government sources. They are sometimes distrusted entirely, especially at the national level. This has been exacerbated by various government shutdowns and sweeping changes in policy such as the removal of climate change information and research from official government websites. In the midst of this, the author noticed a continually increasing aversion to government sources by a number of students, particularly in first year writing courses where students are beginning to learn about various types of sources for academic writing and research. This observation was based on personal experience, and thus this article seeks to understand if this anecdotal evidence is supported by the experience of others in the field.

To better understand how other librarians are reacting to the changing perception of government sources, the author distributed a survey to academic librarians who teach about and conduct consultations of government information at all levels of government. This was intended to collect qualitative and quantitative information about student engagement, perceptions of user trust in government sources, librarian experience with government sources, the biggest issues librarians are seeing related to government information, and how librarians' strategies and approaches have changed under the Trump administration. The information conveyed in this paper is intended to help librarians become more aware of this issue as they introduce and discuss government source with users so that they can identify more novel ways to approach and prepare for these conversations and what they will often be facing in terms of user perception of government sources.

\section{Literature Review}

Government information has long been seen as a valuable source of information in academia by government documents librarians and many librarians specializing in other subject areas, while also acknowledging the complexity and confusion that government sources bring. Its role as a non-traditional academic source simply means that it needs to be discussed and taught by librarians in a variety of academic settings. Government sources are excellent examples to use to illustrate complexity in authority, point of view, and audience for exercises in information literacy and evaluation (Hogenboom 2005). Not only do government publications stand on their own as sources that have value in the research process, they can also help illustrate some difficult information literacy concepts with acuity as Hogenboom notes (p. 464): "Using government information to teach the skills necessary to evaluate sources not only teaches students to understand and use government information but also gives them skills they can apply to all kinds of information throughout their college careers and beyond." 
Dubicki and Bucks (2018) emphasize the value in incorporating government sources into assignments and research in various academic disciplines since this information will likely make an appearance during professional careers and in daily civic life after students' higher educational pursuits are obtained. Rogers (2013, p. 8) also stresses the importance of impressing the value of government sources onto users because "after graduating, citizens and residents are unlikely to think of answering a question or satisfying an information need as 'I need a book' or 'a newspaper article,' but 'I need information about this subject,' whatever the format." Pointing out government information's value and relevance in these cases can help users overcome their intimidation and initial inclination to overlook government information. In addition, including government information into information literacy classes "not only provide[s] lifelong access to information, but also help[s] us cultivate the inner resources to question and evaluate the nature of information" (Rogers 2013, p. 9). In this way, government sources serve as a valuable teaching tool for discussing authority, audience, and bias. However, this tendency to focus on government source evaluation was not always so common.

Historically, government information has been acknowledged as a valuable source of information for academics and students as primary and secondary sources on topics of all kinds, and in the past many librarians - although not all - and patrons simply assumed that government sources were generally credible and authoritative and instead focused more on the complexity of the resources and their potential relevance. For example, Sheehy and Cheney (1997) focus on the instructional approach used in a credit-bearing course on government information research skills for undergraduates taught at Pennsylvania State University in the 1980s and 1990s. They highlight a need for librarians to teach users about the "structure and function of government" so that it is easier for students to identify which agencies might produce relevant publications for a research question. From their article, it is apparent that the biggest question at that point in time was relevancy to the research topic with the foregone conclusion that government sources were credible simply because they were published by the government. Even with the advent of the internet, this tendency to take government sources at face value continued: Brunvand and Pashkova-Balkenhol (2008) claim that students should be "able to infer that a .gov URL indicates a valuable and trustworthy resource" (p. 205). Again, this shows a tendency to see government sources as credible across the board rather than evaluating each source objectively.

The rise of the internet and the spread of information, including government information, that came with it meant that undergraduates were also using government sources more often as these materials become more easily accessible via websites with a .gov extension (Brunvand and Pashkova-Balkenhol, 2008). Even in the early 2000s, students were inundated with government information on a daily basis through the media they consumed, giving them some idea of the complexity and various purposes of government information in relation to bias and credibility (Hogenboom 2005). As Hogenboom notes:

Students who even occasionally watch, listen to, or read the news are aware that those who govern have agendas beyond reporting the objective truth of a particular situation. 
When they can see how the political beliefs of a particular presidential administration affect the information it disseminates or how an agency's accomplishments are described differently in its glossy annual report versus its reports to Congress, they have mastered an important skill (p. 456).

However, faculty instructors usually discourage use of internet sources, and government sources are largely online. Karn-Carmichael and Weaver (2016) also note the tendency for teaching faculty and students to group government sources into a non-scholarly category as they are primarily accessed via the internet and therefore often deemed unacceptable for use in scholarly research and writing. Another reason that government information is not being used in a scholarly context is because it "often lacks authorship from a noted scholar, and looks and reads differently than the more traditional 'academic' sources students are encouraged to use" (Karn-Carmichael and Weaver, p. 14). Coupled together, this means government sources are often underutilized and automatically discounted or distrusted by users without proper library instruction on how to evaluate them for inclusion into various types of scholarly discourse.

Hogenboom and Woods (2005) also discuss the often negative perception of government sources by users and by librarians in the realm of instruction and information literacy, but they present three different approaches to teaching government sources, all depending on the purpose of a particular instruction session. The first is a traditional approach which emphasizes government literacy (who produces it, how is it organized, disseminated etc.). Next is an information cycle approach which focuses on associating government sources with other publication types (newspapers, scholarly publications, etc.) to help users understand audience, style and format, and content of government publications that could also be categorized in these publication types. Finally, the authors hone in on deep critical thinking and information literacy that incorporate the tenets of the first two approaches to encourage students to evaluate government sources by thinking about validity, authority, and bias as well as how context and deception can play a part in how government information is generated and used. This is beginning to hint at the larger issue that came to fruition in the literature in the late 2000 s and 2010s of looking at the bigger picture of government information and evaluating these sources using various data points and seeing that they can often have a biased side to them that needs to be taken into account.

The rise of the internet as a source of information for personal and academic purposes not only brought to the forefront the issue of bias and credibility but also the issue of ephemeral versus longstanding access to information of all kinds. In recent years, US government information has taken center stage since it engenders a right to sweeping access by the people, unlike other proprietary types of information products, but even before the advent of the internet and the tense political climate of today, government information has been disappearing from the public record for a variety of reasons, both intentionally and unintentionally. In the 1980s and 1990s, the American Library Association's Less Access to More Information series tracked and notified the library community about government documents not being made accessible due to politics and political battles during that time. The rise of the internet in the late 1990s and early 2000s 
meant that more people could conveniently access government websites and online government information. However, this came with disadvantages. Notess (2000) pointed out issues with websites disappearing and URLs failing because of server, format, or location changes even in the early days of the 2000s. In those early days, librarians were already making recommendations of where to look and search strategies for tracking down missing websites or web pages.

Since Notess' article in 2000, the internet has grown exponentially and so has the amount of online government information. In 2013, the Government Publishing Office estimated that $97 \%$ of government information is born digital with that number likely higher today, exacerbating the problem of disappearing information with the astronomical volume of webpages. Jacobs and Jacobs (2017) underscore Notess' observations and go a step further to assert that disappearing government information has always been a problem regardless of format as well. They discuss how print documents that do not get distributed to libraries for access purposes are just as susceptible, but also focus on the internet world and how digitally-born government information is largely not being preserved for long-term use and that it is more susceptible to change and alteration. They discuss the End of Term archive as one initiative of a variety of web archiving entities working to preserve government websites. To help put the current issue in scope, according to Jacobs and Jacobs, the End of Term web archive gathered images of 310 million unique URLs for the website crawl in 2016 before President Trump took office.

To see if there were differences in access at varying levels of government, Sproles and Clement (2009) tracked federal, state, and local electronic information from month to month in 2008 to see how and if it disappeared. They found that government documents at all levels of government are disappearing at alarming rates, particularly state and local electronic government information.

While disappearing government information has always been an issue regardless of administration, since the Trump administration took office in 2016 this issue has intensified in a variety of ways that can only be connected with the administration itself. Flynn and Hartnett (2018) expound upon the ways that obfuscation and disappearing information have been prevalent in Trump's administration and that government information is in a perilous place right now for long-term access. They particularly note President Trump's confusing use of his Twitter account in muddying the waters around if he can officially establish policy via his personal account. They point out that the use of social media as President Trump's main communication with the American public obfuscates what is credible or authoritative for government policy and makes students and the public question that which is official.

In terms of disappearing data in the context of political turmoil and beliefs, Golbeck (2018) discusses the removal or suppression of data that does not agree with administration policies, particularly under the Trump administration. The author points to a variety of recent examples, including the removal of climate change language from the EPA website and suppression of 
various federal agency social media accounts. The tenuous situation of suppression of government data raises the question of trust in government sources generally.

Golbeck's assertion is underscored by what Twizeyimana and Andersson (2019) find in their literature review about the perceived public value of e-government. Related to trust of government, they point to articles that conclude that public trust is gained by providing the public with better access to government information and services and that a core value of e-government is the ability to inspire trust by making it easier for users to access this information (Rose, Persson, and Heeager, 2015; Rose, Persson, Heeager, et al., 2015). The growing concern with disappearing online government information means that individuals are also likely to have a burgeoning distrust of these sources.

With this heightened awareness of disappearing information under the Trump administration, the kneejerk distrust is obvious even when it is not warranted. For example, there was widespread concern and attention from librarians and researchers on a Department of Interior request in October 2018 to the National Archives and Records Administration (NARA), the agency tasked with keeping and providing public access to federal government records, that seemed like a move to destroy large amounts of records related to land acquisition, fish and wildlife critical habitats, environmental impact statements and other seemingly important information and documents. The NARA responded in a blog post to say that this was a "normal request to consolidate and revise [the Department of Interior's] previous records schedules into 'big buckets'" (Ravanbakhsh 2018, para. 2). Even though NARA clarified why this particular case - and retention schedules in general - are not meant to destroy important records, this situation helped reveal how little the public understands the intricacies of agency responsibility in providing long-term access to government information and how trust in government is directly tied to (perceived) access to information.

The increasing partisan conflict that has characterized the political environment of the last few years is not lost on our users, and the effects of this tense political climate can be seen in the classroom when discussing all types of sources. Bluemle (2018, p. 268) points to "loss of trust in traditional sources of authoritative information" as a direct consequence of a post-facts world after the 2016 election. Bluemle particularly pinpoints academia, mainstream news organizations, and government organizations as sources that would typically be recognized as authorities of information but have lost their influence and legitimacy as reliable sources. The author goes on to discuss the idea of cognitive authority in the post-facts climate wherein authority does not solely rely on expertise or accuracy, and instead allows emotion and charisma to influence individuals into giving authority based on their perceptions rather than on facts. One solution that Bluemle posits is for librarians to "give more attention to the role emotion plays in reasoning and decision-making" and to consider users' personal beliefs and political biases when talking about trust and authority of sources (p. 278). Cooke $(2018$, p. 7$)$ uses similar language when discussing the pervasiveness of fake news in the post-truth era--in line with Bluemle's post-facts era--wherein "consumers will deliberately pass over objective facts in favor of information that agrees with or confirms their existing beliefs, because they are 
emotionally invested in their current mental schemas or are emotionally attached to the people or organizations which the new information portrays." This supports Bluemle's assertion that certain organizations and individuals will be believed or garner more trust while others will fall out of favor simply depending on the emotional allegiance of a particular patron.

Glisson (2019, p. 462) noticed the tendency for students to distrust the news media and scientific research in the wake of the 2016 election and increasing political partisanship, which "calls into question the relevance of factual evidence." This lack of trust is paralleled with that of academic and government sources as well in our current political climate. Fake news and disinformation are terms that have become mainstream and "foster cynicism in our students" ( $p$. 462). Glisson emphasizes the librarian's role in helping students "discern fact from fakery" ( $p$. 463 ) in pushing students to go past their personal biases to evaluate sources. Both Bluemle and Glisson's articles harken back to the idea of confirmation bias, which can take various forms but ultimately results in an individual interpreting or favoring evidence that agrees with their preexisting beliefs (Nickerson 1998). Regardless of intent, since the Trump administration took office there is a trend towards a broad lack of trust when it comes to government sources.

\section{Methodology}

In spring 2019, the author developed a survey for academic librarians in the United States who work with government information at all levels of government to better understand how librarians are reacting to the changing perception of government sources when teaching or discussing government sources with users. The survey was designed to collect qualitative and quantitative information about a variety of factors: volume of sessions, subject areas requesting this type of teaching, student engagement, particular issues librarians encounter when discussing government information, perceptions of user trust in government sources, and how their strategies and approaches have changed since the 2016 election.

The study was approved by the Institutional Review Board and determined to be exempt from human subject research. The 24-question Qualtrics survey was sent out to various academic library listservs and government information- and data-focused listservs across the US. The survey was open from June 13 through July 5, 2019, and a reminder email was sent out halfway through the open period. The survey garnered 166 responses. However, 44 responses were deleted as the respondents did not answer questions past the beginning demographics section. This left 122 responses which were used for qualitative and quantitative analyses.

Results were exported from Qualtrics as a CSV file into Google Sheets for recoding and analysis. Quantitative data analysis was conducted in SPSS with a p-value of statistical significance set at 0.05 or less. Qualitative data were analyzed for themes using a mixed methods approach where the author went through various free-text responses and coded for similar emerging themes and topics in Google Sheets. 


\section{Findings \& Discussion}

Of the 122 academic librarians surveyed, 74 per cent were from a university of some type, 15 per cent were from a liberal arts college or institution, 4 per cent were from community, technical or tribal colleges, 2 per cent were from law institutions, and 4 per cent were from other types of special academic libraries (one person did not respond to this question).

The geographic distribution of respondents was fairly dispersed with a higher percentage of respondents in the Midwest Census region. There were 38 per cent in the Midwest Census region, 27 per cent in the South, 19 per cent in the West region, 15 per cent in the Northeast, and 1 per cent in Puerto Rico.

Without including respondents in Puerto Rico since it is a US territory, 47.5 per cent of respondents $(n=57)$ were in a state won by the Democrat nominee in the 2016 election with 52.5 per cent of respondents $(n=63)$ in a state won by the Republicans (Maine was coded as Democrat since three of its four electoral votes went to the Democrats).

In terms of librarians' duties and responsibilities, 55 per cent $(n=67)$ were Federal Depository Library Coordinators, individuals designated in their library to steward access to federal government information in all formats received from the Government Publishing Office. Whether or not responsibility for government information is formally a part of respondents' job duties, 76 per cent spend less than half of their time supporting access to government information while 24 per cent spend more than half of their work time on said activities. Respondents also listed a variety of other duties as formally part of their position responsibilities, with those duties most associated with instruction and research support topping the list (Figure 1). Two-thirds said that government information at any level of government (international, federal, state/local) is part of their formal job responsibilities. 


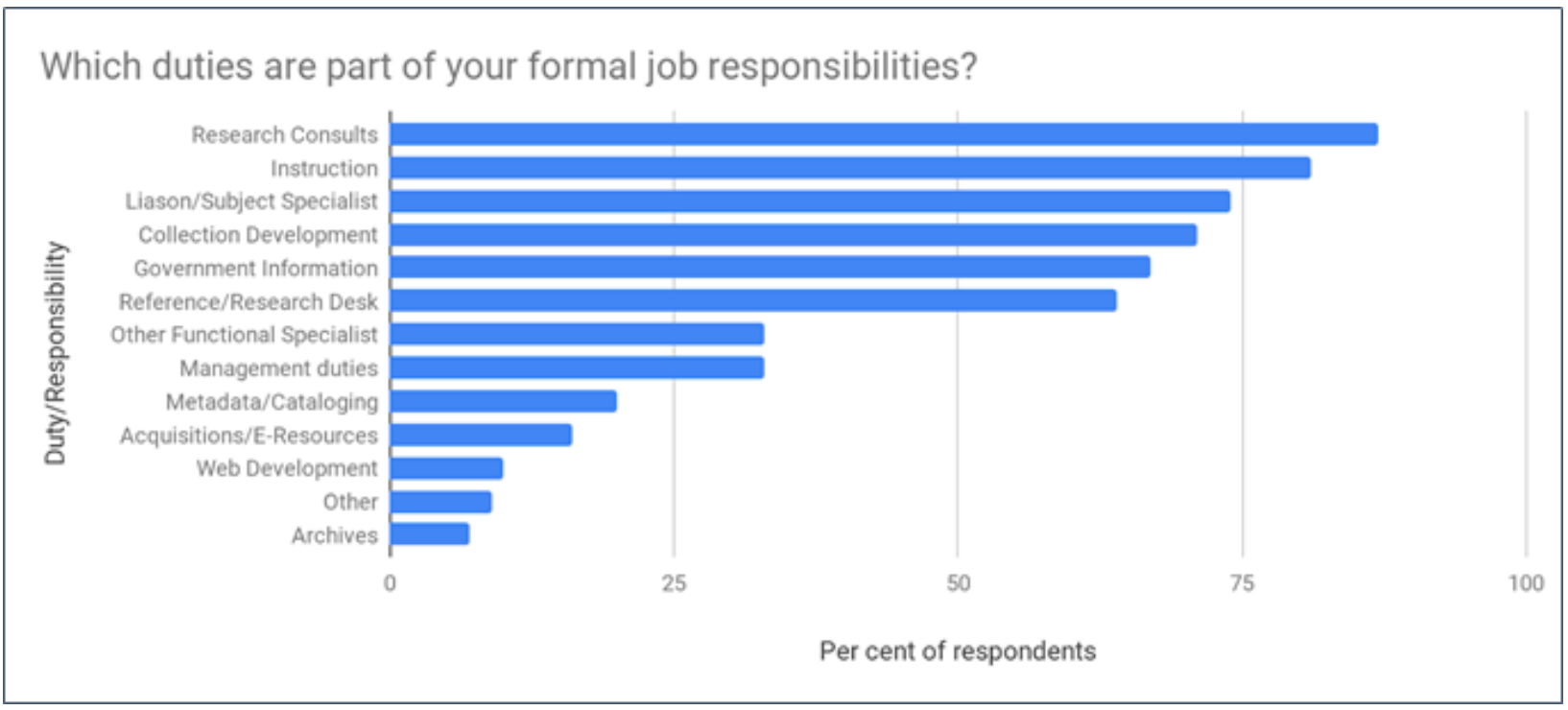

Focusing on experience working in libraries, the highest percentage (17 per cent) of respondents have worked in libraries for 5-9 years. Alternatively, the highest percentage (19 per cent) of respondents indicated that they have only worked with government information for $0-4$ years. Library experience overall skews higher in the survey whereas government information experience skews a bit lower. This is likely because responsibility for this area is often assigned after someone retires or leaves an institution, and there are few positions where government information is the only or primary job duty.

\section{Concerns about access to government information}

When asked about how strategies or approaches for teaching or discussing government information have changed since the 2016 general election, many respondents found it necessary to touch on the topic of disappearing government information, particularly online information found via government websites, in their teaching and consultations. The overall issue of disappearing government information was expressed by respondents in a variety of ways, although all pointed back to this core issue; one respondent described it as "suppression of information" while another mentioned "unreliability in discovery and permanency" of web pages. Another called this "take-down" of government information.

Furthermore, respondents commonly mentioned the take-down or disappearance of government information as a main source of distrust for users even as users become more interested in government information and current events: "I have found much more interest since the 2016 election. Most of my students, faculty, [and] other users are concerned with how trustworthy government information is. There is also fear that current information and information not in agreement with the present administration will disappear." Others noted disappearing information or data due to content that did not fall in line with the current administration's preferred narrative. As highlighted in the literature, link rot and the ephemerality of government web pages have long been issues, but they are becoming more acknowledged 
and known in the wider user community since the 2016 election, particularly because of the EPA climate change webpages being changed by the Trump administration. While disappearing online information is usually not caused by nefarious motives, specific cases like climate change rhetoric have introduced an impulsive belief by users that this is the norm for government information across subjects and agencies.

Respondents cited the news media coverage of disappearing government information and data as a main reason for users being aware of this issue, particularly with regard to hot topics such as climate change and the environment. As one respondent explained, "My general feeling is that there is more concern about the government 'removing' or 'hiding' certain types of information (esp[ecially] as regards subjects such as climate change) due to the amount of pervasively negative press regarding every aspect of the current administration." While news coverage of this issue has brought about a lack of trust by many users as cited by the respondents, it also has provided an opportunity for librarians who work with users around government information to speak about broad longstanding preservation and access issues for online content such as link rot, records retention schedules, and server issues and the idea that this happens regardless of who is in the White House. For instance, one respondent gave examples of particular topics that can now more easily be introduced such as "the importance of depository arrangements," referring to the depository program that provides and facilitates access to federal government information, and the "networks of libraries cooperating to preserve and provide access to govt [sic] info."

Many respondents still emphasized the current administration's focus on suppressing information but want to make sure users understand the many ways access to government information can be negatively impacted:

In some cases, there actually has been a deliberate de-emphasizing of information on these topics by said administration; in others, this is not the case, but things are so politicized and polarized that even an innocuous (typical) loss of government information (eg, an agency switching servers and not updating links or not transferring all previously available documents), something that would have attracted no notice during previous administrations, is perceived as a deliberate attempt at obfuscation.

A number of respondents pointed out a lack of government literacy on the part of users and colleagues which has added to the distress and confusion during Trump's administration and ultimately contributed to the distrust of government sources. One respondent emphasized a need to explain to users "what is involved when government agencies produce information, statistical, and geospatial information resources, [and] the political and policymaking reasons for producing this information" in addition to the fact that "multiple agencies can be involved in producing this information and in implementing policy in specific subject areas." The idea that users often need more knowledge about how the government works to understand what is happening under the Trump administration is also stressed in the literature. 


\section{Battling fake news and distrust with information and government literacy}

In addition to government literacy, major tenets of information literacy pedagogy appeared in the survey responses. Since the 2016 general election, respondents noted how authority, bias, and credibility have become major focus points when discussing government information. For example, one respondent said that "it has become necessary to offer the caveat that government information can potentially be representative of particularly [sic] policy positions rather than reflective of careful, deliberate study. Rather, it is always 'authoritative' but not always credible." Or as another respondent put it, "you can have formal authority (e.g. be President of the United States) but not subject authority (e.g. medical knowledge of abortion)." Some respondents noted how they have always touched on these topics when teaching or consulting about government information sources, but that it has become more necessary and more asked for by faculty since President Trump took office. Even much of the literature from pre-2016 does not directly address the idea of why government information is usually authoritative but not always credible and more often assumes that because it is a government source it should be trusted. In the current political landscape, this blanket acceptance is not admissible for users and therefore underscores why government information instruction is more necessary than ever.

Information literacy and overall government literacy are the main combatants to another common denominator in the survey responses: fake news. Many respondents said that they had been asked to respond to fake news in their government information teaching, consultations, and library research guides. Respondents spoke about critically evaluating government data and information, ascertaining validity, and discussing authority and bias in the face of the fake news predicament related to government sources and the current presidential administration.

In addition, respondents noted that the news coverage of this administration and its policies around various contentious topics like climate change, immigration, and abortion - to name a few - have given them more timely and relevant examples where government information plays an important role in sources on a topic:

For good or ill, the prominence of civil rights issues, health and medical issues, investigations like Mueller, natural disasters, etc. in news coverage means as a teacher you can instruct with that as a relevant example of what kinds of information are needed to understand it fully, what information sources are available, and how to critically analyze information even when it comes from a "trusted" source.

Rogers (2013) and Hogenboom (2005) also noted this even before the 2016 election and the ascendancy of the Trump administration. This has always been the case but the laser focus of the media on President Trump and his cabinet members has put even more emphasis on how well government sources are suited to teaching users about critical information literacy concepts, and how emotion can play a part in how we orient our trust of sources. 
In the survey, respondents were asked about how often they teach certain topics or skills during the course of an instruction session or consultation related to government information with options to indicate whether that topic was taught always, often, occasionally, rarely, or never in their work (Figure 2). Teaching about government statistics and data topped the list with 59 per cent of respondents teaching the topic always or often, closely followed by online subscription or non-government free resources at 58 per cent and government websites at 54 per cent. Primary sources were taught always or often 50 per cent of the time, and respondents reported teaching law and legal resources at 36 per cent. At the other end of the spectrum, government literacy and bias or authority were taught rarely or never 54 and 46 per cent of the time by respondents, respectively. These results point to the idea that, often, librarians are teaching to a particular format or resource and not always digging into how or why one should evaluate or trust government sources, although the literature and the qualitative responses show that this is becoming increasingly important.

\section{How often do you do instruction or consultations about the following topics related to government information?}

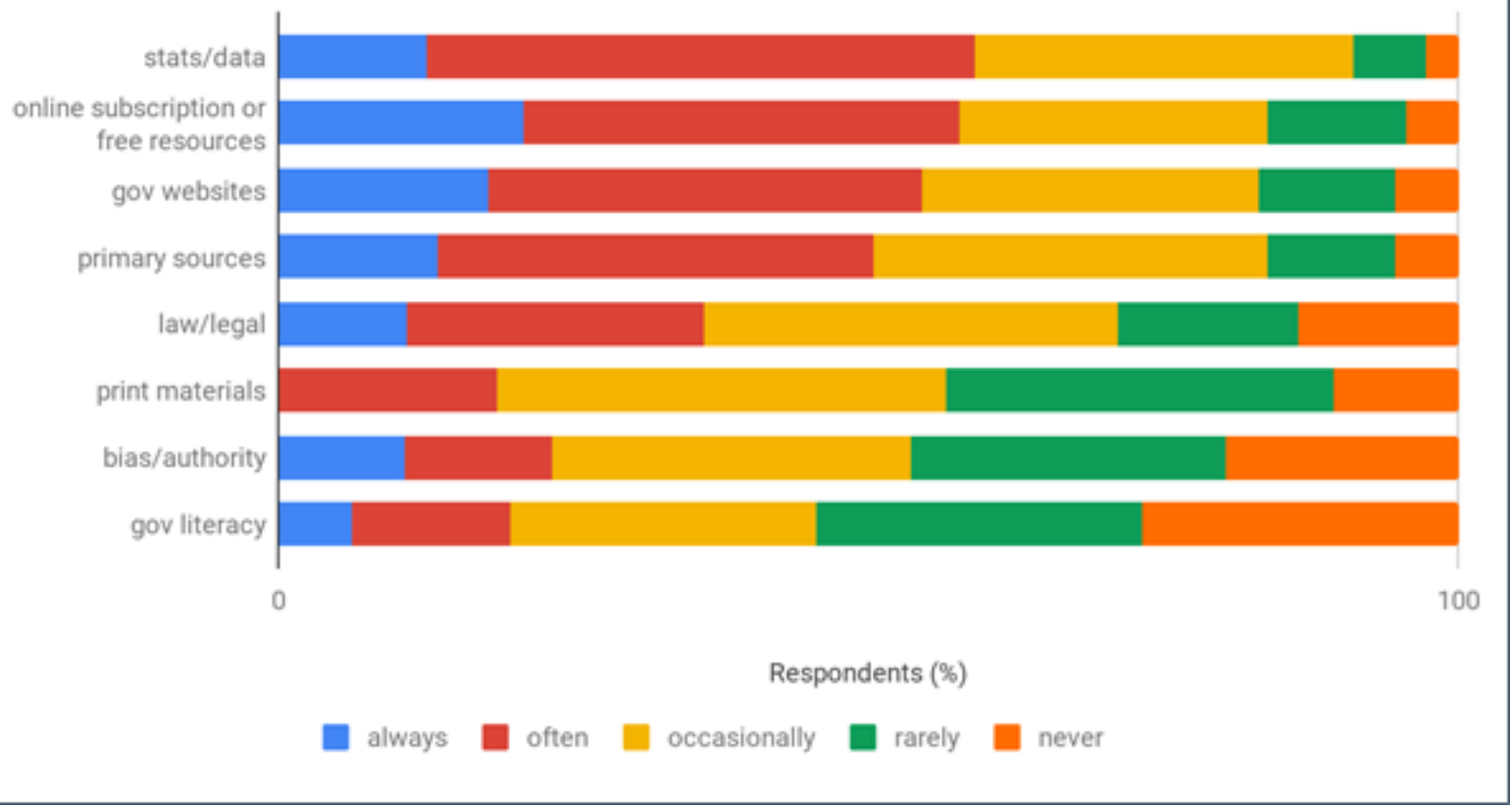

With information literacy playing a large part in the free-text responses, the author hypothesized that bias and authority as well as government literacy would be taught more often than was reported. In relation to user trust of government sources it was found that those librarians who teach about bias or authority in government information contexts always, often, or occasionally have users that are less likely to trust government information after the 2016 election ( $F=9.857$, $\mathrm{df}=1, \mathrm{p}=0.002$ ). These librarians who are actively teaching bias in and authority of government sources may be teaching it because they have noticed their patrons are particularly struggling with trust of these sources since the election or have always taught this in the course of working 
with government information. However, there is no statistically significant difference in users' trust of government information for those librarians who teach government literacy always, often, or occasionally versus those who teach it rarely or never $(F=0.010, d f=1, p=0.0922)$. This is surprising as authority and bias in evaluating government sources and government literacy go hand-in-hand: understanding how the government works is key to understanding the process of how government information is created and for what purposes. It is also difficult to unmarry these two concepts as they are so intertwined; it is also possible that respondents are touching on government literacy in the course of discussing bias or authority even if they may not realize it or name it as such. For example, in the free-text responses, only a handful specifically mentioned teaching about government processes and literacy whereas many highlighted authority and credibility in the context of government information, so perhaps respondents see government literacy as encompassed within bias and authority although they were listed separately for this particular question. As the two examples below show, respondents also mention discussing these information literacy skills using government information because they work well to integrate with current events that students or users would have seen in the news.

I also highlight government information as an authoritative source of information on controversial topics (e.g. vaccinations, abortion, border control) that students may be encountering in the news.

The climate has provided an opportunity to highlight and discuss some important aspects of government information (e.g. authority, credibility) because topics in the news match well with them.

\section{The politicized environment around government information}

When asked if there are particular levels of government where respondents are seeing a decline in trust of government sources, most mention the federal level. However, a few mention a decrease in trust at the state level, especially if that state is typically highly politically conservative or seen to be aligned with the current federal administration and its beliefs. Relatedly, information published and disseminated by federal agencies is mentioned as being more distrusted if the leader of the particular agency tends to change with who is in the White House or if it is an agency which oversees a contentious topic or area. As one respondent remarked, "I also am much less trusting of material found on agencies [sic] pages that report directly to the president." Individual users' political leanings are also affecting how they perceive government information:

There has been both an increase in interest in government information and in distrust of some government information. Also, the response seems very partisan. Individuals who may not have trusted the information before because of perceived biases in the administration now trust it and vice-versa.

As Bluemle (2018) noted, students bring their personal experiences and beliefs to evaluating sources and determining who or what they consider authoritative or trustworthy, and the same shows in the responses. Instead of evaluating government sources objectively, librarians and 
users alike seem to be leaning into their own political underpinnings when considering the trustworthiness of government information.

For example, respondents note that they have to be more careful about their own political leanings and personal biases in how they present or talk about government information to ensure a more objective evaluation of the source. Keeping in mind users' bias and librarians' bias underscores the information literacy work discussed above in evaluating a source on its own merits or drawbacks rather than viewing it through a personal political lens. As one respondent put it:

I find that I need to be far more careful about sounding as if I am 'taking sides' in the political debates of our times. I need all students to feel welcome, and on a liberal campus like mine, more conservative students are struggling to feel welcomed in the classroom. This is especially true of my international students.

In the context of political leanings, quantitative analysis explored how academic institutions in blue (Democrat) or red (Republican) states for the 2016 election might have fared with user trust of government sources. Analysis found that there is no statistically significant difference in librarians' level of perceived user trust in government sources since the 2016 election based on whether or not the state in which the institution resides is in a state that went Democrat or Republican in the 2016 election $(F=0.822, d f=1, p=0.367)$. This could be because academic institutions are insulated communities in their own right and do not always reflect the political and societal tenets of the state around them. Academia also tends to be more liberal minded generally, so the voter beliefs of a particular state would not necessarily always align with the academic population.

\section{The value and importance of government information}

Overall, the survey revealed a growing distrust of government information since the 2016 general election, but also more interest since this type of information is on the forefront of news and media. Respondents pointed out that some level of doubt and questioning on the part of users provides a great opportunity to talk more about government sources and their value in a variety of contexts. As illustrated in the literature dating both before and after the 2016 election, librarians note the role that government information takes in the information lifecycle and its value to users during their academic careers and beyond as citizens. In alignment with the literature, one respondent remarked that they are "teaching 'gov docs as literature' more often now" than before the 2016 election. Many respondents also remarked on government sources as being authoritative in many ways and often the only source of information on particular topics, especially in relation to data and statistics. Normalizing government sources as important and valuable while still teaching evaluation is key in the current government landscape.

In addition to providing an opportunity to discuss how government information can be appropriate for academic research and scholarly pursuits, this tumultuous political environment also leaves an opening to more easily bring up information literacy conversations in government 
information consultations and instruction sessions. Particularly, helping users understand the role of author and authority for individual government documents (especially those with a particular agency employee author) versus the larger agency or federal government will help demonstrate the wide variety of expertise and scholarly knowledge of government agency employees and their version of academic output in government documents. As this published information will be one of the only types of scholarly information largely available to them after leaving higher education, it is imperative that academic users fully understand how government information can be scholarly and reliable depending on the document or specific government source. Similarly, respondents emphasized not wanting to demonize federal agencies and other government organizations that are trying to do business as usual and publish their reports and documents that usually have no underpinning political debate or partisanship.

\section{Conclusion}

In the wake of the 2016 presidential election and ascendancy of the Trump administration, academic librarians and users alike have been wrestling with how to view government sources. The highly politicized government environment has leaked into the classroom because this information so inundates our daily lives, especially in the age of social media, but the high profile nature of government information also allows librarians to discuss these sources in light of authority and credibility. While survey findings showed a higher distrust of government sources, the time is ripe for librarians to step in and demonstrate how to objectively evaluate these sources and see past our own political leanings to realize how government information can be valuable in scholarly work and beyond. The complex and difficult nature of government sources often means that they are not included in information literacy sessions, but the literature and survey findings emphasize the growing need and user interest in discussing these sources. It is up to the librarian to show students how to take a step back and look at the whole landscape of government publishing and information creation so that these valuable sources can continue to be utilized and appreciated despite highly partisan politics and presidential administrations.

Extreme partisanship does not look like it is fading anytime soon, and therefore librarians who teach others about government sources can become more aware of this issue and continue to discuss how we frame the narrative around government information at all levels of government. This article can start the conversation of strategies librarians can incorporate and heighten librarian awareness when doing this work. In this vein, future research building upon this article could dig into more in-depth interviews of librarians to determine more strategies for teaching in this political climate and do more evaluation of which types of government sources are facing more backlash and distrust.

\section{References}

Bluemle, S. R. (2018), "Post-facts: information literacy and authority after the 2016 election", portal: Libraries and the Academy, Vol. 18 No. 2, pp. 265-282. 
Brunvand, A. and Pashkova-Balkenhol, T. (2008), "Undergraduate use of government information: what citation studies tell us about instruction strategies", portal: Libraries and the Academy, Vol. 8 No. 2, pp. 197-209.

Cooke, N. A. (2018), Fake News and Alternative Facts: Information Literacy in a Post-Truth Era,

Dubicki, E. and Bucks, S. (2018), "Tapping government sources for course assignments", Reference Services Review, Vol. 46 No. 1, pp. 29-41.ALA Editions, an imprint of the American Library Association, Chicago, IL.

Flynn, K. A. and Hartnett, C. J. (2018), "Cutting through the fog: government information, librarians, and the forty-fifth presidency”, Reference \& User Services Quarterly, Vol. 57 No. 3, pp. 208-224.

Glisson, L. (2019), "Breaking the spin cycle: teaching complexity in the age of fake news", portal: Libraries and the Academy, Vol. 19 No. 3, pp. 461-484.

Golbeck, J. (2018), “Data we trust--but what data?”, Reference \& User Services Quarterly, Vol. 57 No. 3, pp. 196-99.

Hogenboom, K. (2005), "Going beyond. gov: using government information to teach evaluation of sources", portal: Libraries and the Academy, Vol. 5 No. 4, pp. 455-466.

Hogenboom, K. and Woods, S. (2005), "Choosing the right approach: three models for teaching government information sources”, Research Strategies, Vol. 20 No.4, pp. 397-408.

Jacobs, J. A. and Jacobs, J. R. (2017), "Government information: everywhere and nowhere", GPLNE, 24 October 2017, available at:

https://freegovinfo.info/wp-content/uploads/2017/10/Disappearing-govt-info-GPLNE-notes.pdf (accessed 9 August 2019).

Karn-Carmichael, K. and Weaver, K. D. (2016), "Giving government information the green light: creating and using the stoplight evaluation guide in the information literacy classroom", DttP: Documents to the People, Vol. 44 No. 1, pp. 14-18.

Nickerson, R. S. (1998), "Confirmation bias: a ubiquitous phenomenon in many guises", Review of General Psychology, Vol. 2 No. 2, pp. 175-220.

Notess, G. R. (2000), “Finding online government publications”, EContent, June/July, pp. 67-70. 
Ravanbakhsh, A. (2018), "Department of Interior updating their records schedule", available at: https://records-express.blogs.archives.gov/2018/10/26/department-of-interior-updating-their-rec ords-schedule/ (accessed 9 August 2019).

Rogers, E. (2013), "Teaching government information in information literacy credit classes", Georgia Library Quarterly, Vol. 50 No. 1, available at:

http://digitalcommons.kennesaw.edu/glqhttp://digitalcommons.kennesaw.edu/glq/vol50/iss $1 / 9$ (accessed 25 July 2019).

Rose, J. et al., (2015), "Managing e-government: value positions and relationships", Information Systems Journal, Vol. 25 No. 5, pp. 531-571.

Rose, J., Stouby Persson, J. and Tordrup Heeager, L. (2015), "How e-Government managers prioritise rival value positions: the efficiency imperative", Information Polity, Vol. 20, pp. 35-59.

Sheehy, H. M. and Cheney, D. (1997), "Government information and library instruction: a means to an end", Journal of Government Information, Vol. 24 No. 4, pp. 313-330.

Sproles, C. and Clemons, A. (2009), "Permanent electronic access to government information: a study of federal, state, and local documents", Electronic Journal of Academic and Special Librarianship, Vol. 10 No. 2, available at:

http://southernlibrarianship.icaap.org/content/v10n02/sproles_c01.html (accessed 23 July 2019).

Twizeyimana, J. D. and Andersson, A. (2019), "The public value of e-government -- a literature review”, Government Information Quarterly, Vol. 36 No. 2, pp. 167-178.

U.S. Government Publishing Office. (2013). “GPO's Federal Digital System Reaches 500 Million Retrievals." Press Release, 1 May 2013, No. 13-19, available at:

https://www.gpo.gov/docs/default-source/news-content-pdf-files/2013/13news19.pdf (accessed 1 October 2019). 